\title{
Influence of quenching parameters on mechanical properties and conductivity of 7A09 aluminum alloy
}

\author{
D. Shi*, K. Kang, Z. Chen, G. Gao \\ Department of Materials Science \& Engineering, Harbin University of Science \& Technology, \\ Harbin 150040, P. R. China
}

Received 7 June 2016, received in revised form 22 July 2016, accepted 17 August 2016

\begin{abstract}
The influence of solid solution temperature, water quenching temperature, transfer time before quenching and delay time after quenching on the mechanical properties and conductivity of 7A09 aluminum alloy were investigated. The mechanical properties and conductivity keep relatively stable at the range of $460-490^{\circ} \mathrm{C}$. When the transfer time before quenching is more than $20 \mathrm{~s}$ or the water quenching temperature is higher than $40^{\circ} \mathrm{C}$, the strength and conductivity drop remarkably while the elongation keeps rising all the time. Before the delay time is $8 \mathrm{~h}$, the strength drops quickly while the elongation and conductivity rise continuously. In the range of 8-24 h there is an opposite change compared to the previous $8 \mathrm{~h}$. Once the delay time exceeds $24 \mathrm{~h}$, all the properties become stable. The optimal quenching parameters are as follows: the solid solution temperature is $460-490^{\circ} \mathrm{C}$, and the water quenching temperature and the transfer time before quenching are below $40^{\circ} \mathrm{C}$ and $20 \mathrm{~s}$, and the delay time after quenching is below $2 \mathrm{~h}$ or above $24 \mathrm{~h}$.
\end{abstract}

Key words: quenching parameters, 7A09 aluminum alloy, mechanical properties, conductivity

\section{Introduction}

As a sort of high strength aluminum alloy of Al-Zn-Mg-Cu series, 7A09 has been widely used in the major structural parts such as aircraft skin in the aerospace field instead of the steels because of its high strength and hardness, low density, good corrosion resistance and wear resistance $[1,2]$. Al-Zn-Mg-Cu series aluminum alloys were produced by the method of the electromagnetic semi-continuous casting [3, 4], and then their properties were improved by the solution and aging treatment. Consequently, the heat treatment parameters directly affect the mechanical properties and conductivity of 7A09 aluminum alloy. At present, many experimental types of research of optimizing the solution and aging treatment parameters has also been widely reported. Wang's experiments showed that the mechanical properties of thixoformed 7A09 aluminum alloy were obviously influenced by the solution-aging treatment and higher temperature is favorable for the satisfactory solution of alloy elements.
However, the grains grow up when treated at a higher temperature [5]. The effect of solution temperature and solution time on the microstructure and mechanical properties of 7A09 aluminum alloy after isothermal compression was also investigated by Luo et al. [6], and the optimal solution treatment was 55 min at $723 \mathrm{~K}$, followed by rapid quenching in water and an aging treatment for $16 \mathrm{~h}$ at $413 \mathrm{~K}$. The corresponding strength and elongation were $630 \mathrm{MPa}$ and $11.5 \%$, respectively. Microstructural evolution and mechanical properties of 7A09 aluminum alloy in as-received, annealed, cold extruded and heat treated conditions were studied by Chen et al. [7]. Good ultimate tensile strength and elongation were obtained by T6 heat treatment, and the tensile properties for the heat treated condition are a little better than those for the as-received condition. Senkov studied the effect of Sc addition on precipitation strengthening in a direct chill-cast $\mathrm{Al}-\mathrm{Zn}-\mathrm{Mg}-\mathrm{Cu}$ alloy after natural and artificial aging. The microhardness, room temperature mechanical properties and phase composition of the

*Corresponding author: e-mail address: shidequan2008@163.com 
Table 1. Chemical composition of 7A09 aluminum alloy (wt.\%)

\begin{tabular}{cccccccccc}
\hline $\mathrm{Zn}$ & $\mathrm{Mg}$ & $\mathrm{Cu}$ & $\mathrm{Cr}$ & $\mathrm{Fe}$ & $\mathrm{Si}$ & $\mathrm{Mn}$ & $\mathrm{Ti}$ & $\mathrm{Al}$ & $\mathrm{Bal}$ \\
\hline $5.1-6.1$ & $2.0-3.0$ & $1.2-2.0$ & $0.16-0.30$ & $\leq 0.5$ & $\leq 0.5$ & $\leq 0.15$ & $\leq 0.10$ & $\mathrm{Bal}$ \\
\hline
\end{tabular}

alloys were determined after different steps of aging, and the strengthening mechanisms were discussed [8]. However, the influence of the quenching parameters on the mechanical properties and conductivity was rarely studied. Therefore, there is an urgent need to investigate the influence of quenching parameters, which further improve the mechanical properties and conductivity of 7A09 aluminum alloy.

In this paper, the influence of the solid solution temperature, the water quenching temperature, transfer time before quenching and delay time after quenching on the mechanical properties and conductivity of 7A09 aluminum alloy was studied, and the optimal quenching parameters were obtained according to the experimental results.

\section{Experimental}

The experimental materials are hot-rolled 7A09 aluminum alloy plates with the thickness of $70 \mathrm{~mm}$, and their chemical composition is shown in Table 1.

Because 7A09 aluminum alloy cannot be online quenched during the industrial production, it is very important to choose optimal quenching parameters. In this study, through independently altering the solid solution temperature, the water quenching temperature, transfer time before quenching and delay time after quenching, the effects of the four quenching parameters on the mechanical properties and conductivity of 7A09 aluminum alloy were studied. If the solid solution temperature were too high, the over-burning phenomenon in the microstructure of 7A09 aluminum alloy would appear. Therefore, the microstructure was observed by the OLYMPUS-GX71 optical microscope when the solid solution temperature was studied.

The following experiments were designed:

1. When the water quenching temperature, transfer time before quenching and delay time after quenching were kept at $20^{\circ} \mathrm{C}, 10 \mathrm{~s}$ and $2 \mathrm{~h}$, respectively, the solid solution temperature was changed from 420 to $520^{\circ} \mathrm{C}$ with the step of $10^{\circ} \mathrm{C}$.

2. When the solid solution temperature, transfer time before quenching and delay time after quenching were kept at $470^{\circ} \mathrm{C}, 10 \mathrm{~s}$ and $2 \mathrm{~h}$, respectively, the water quenching temperature was changed from 10 to $90^{\circ} \mathrm{C}$ with the step of $10^{\circ} \mathrm{C}$.

3 . When the solid solution temperature, water quenching temperature and delay time after quenching were kept at $470^{\circ} \mathrm{C}, 20^{\circ} \mathrm{C}$ and $2 \mathrm{~h}$, respectively, the

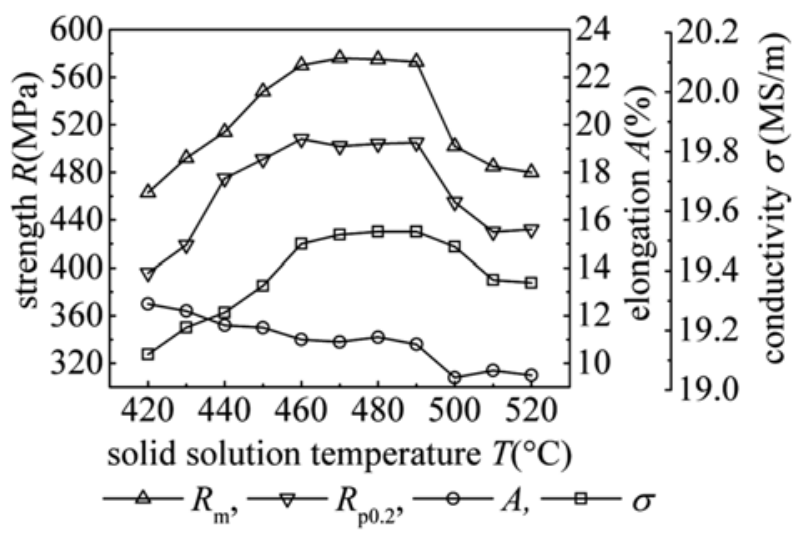

Fig. 1. Influence of solid solution temperature on mechanical properties and conductivity.

transfer time before quenching was changed at $5 \mathrm{~s}$ and from 10 to $60 \mathrm{~s}$ with the step of $10 \mathrm{~s}$.

4. When the solid solution temperature, water quenching temperature and transfer time before quenching were kept at $470^{\circ} \mathrm{C}, 20^{\circ} \mathrm{C}$ and $10 \mathrm{~s}$, respectively, the delay time after quenching was designated to be $1,2,4,8,16,24,48$, and $72 \mathrm{~h}$.

The standard samples were prepared along the rolling direction of the hot-rolled 7A09 aluminum alloy plates according to the GB/T228-2010. The samples were heated in the electric resistance furnace with the accuracy of $\pm 2{ }^{\circ} \mathrm{C}$, and the time of holding at the temperature was $1 \mathrm{~h}$. Then the samples were quenched according to above experimental design, and artificial aging treatment at $140{ }^{\circ} \mathrm{C} / 16 \mathrm{~h}$ was carried out. The mechanical properties (tensile strength $R_{\mathrm{m}}$, yield strength $R_{\mathrm{p} 0.2}$ and elongation $A$ ) were measured by the CSS-44100 universal testing machine. The conductivity $\sigma$ was measured by the QJ57P DC double bridge (produced by Zhengyang Instrument Co., Ltd., Shanghai, China) with the precision of $0.05 \%$ according to the GB/T6146-2010.

\section{Results and discussion}

\subsection{Influence of solid solution temperature on mechanical properties and conductivity}

Figure 1 shows the influence of solid solution temperature on the mechanical properties and conductivity of 7A09 alloy. With the increase in the solid 

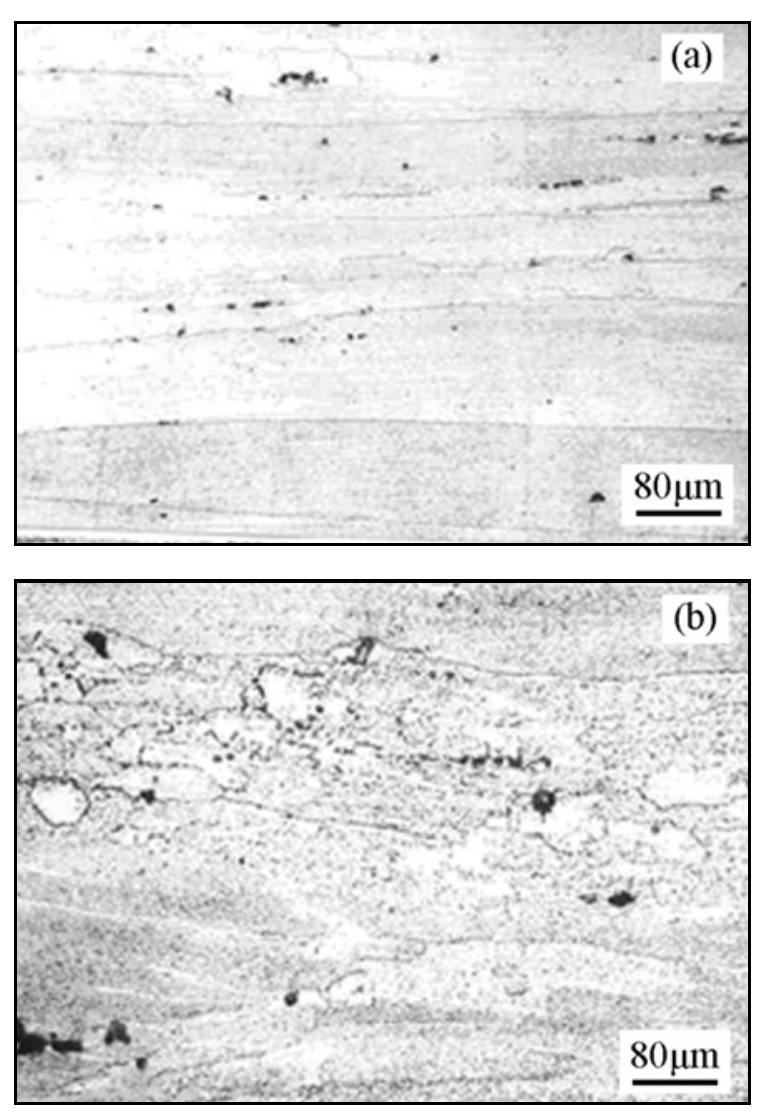

Fig. 2. Microstructure at different solid solution temperature: (a) $470{ }^{\circ} \mathrm{C}$, (b) $500{ }^{\circ} \mathrm{C}$.

solution temperature, the tensile strength $R_{\mathrm{m}}$ and yield strength $R_{\mathrm{p} 0.2}$ rise. Below $460^{\circ} \mathrm{C}$, they rapidly increase. Once the temperature excesses $460^{\circ} \mathrm{C}$, the increase rate becomes very slow. Contrarily, the elongation $\sigma$ drops monotonically along with the solid solution temperature. The change of conductivity with the temperature is similar to that of the strength, from a minimum $19.12 \mathrm{MS} \mathrm{m}^{-1}$ up to a maximum of 19.53 $\mathrm{MS} \mathrm{m}^{-1}$.

This can be explained as follows: The lattice distortion caused by the atoms solved in the Al matrix plays a leading role in the electronic scattering. The higher the solid solution temperature is, the higher the concentration of supersaturated solid solution after quenching is, and the greater the volume fraction of precipitated phase after aging is, the smaller the barrier of the solid solution on electronic is. So, the conductivity rises monotonously with the temperature [9]. As for the strength, when the temperature is increased, the quantity of dissolving second-phase particles increases. As a result, it can promote the amount of the strengthening precipitation phase. Thus tensile strength and yield strength increase. However, the continuous increase in temperature makes the grain recrystallization to grow up, which in turn results

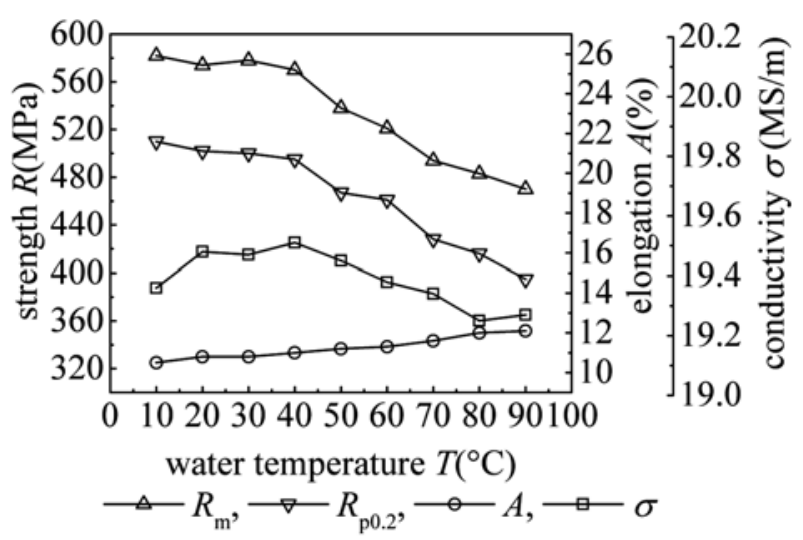

Fig. 3. Influence of water temperature on mechanical properties and conductivity.

in the decrease of the strength $[10,11]$. Therefore, the solid solution temperature cannot be very high. Figure 1 shows that the other properties except the elongation rise rapidly once the temperature is higher than $500{ }^{\circ} \mathrm{C}$. It was attributed to the over-burning. As shown in Fig. 2a, the over-burning was not found in the microstructure. The partially recrystallized grains occur, and they are situated along the deformation direction. Some of the residual phase and the insoluble phase are broken, and they symmetrically arrange along the deformation direction. However, it can be seen from Fig. $2 \mathrm{~b}$ that the obvious over-burning and the complex re-melting grain boundaries appear. According to previous researches $[11,12]$, the precipitated phases continuously distribute in the re-melting grain boundary. The evenly distributed fine precipitated phases inside grains are the coherent GP zone and a small amount of transition phase. Also, some of the large particles randomly distribute in the grain and/or the grain boundaries, and they are the main strengthening phase and the impurity phase.

Therefore, when the solid solution temperature is kept at $460-490^{\circ} \mathrm{C}$, the mechanical properties and conductivity are satisfied, and they are $R_{\mathrm{m}}=575 \mathrm{MPa}$, $R_{\mathrm{p} 0.2}=503 \mathrm{MPa}, A=11 \%$ and $\sigma=19.53 \mathrm{MS} \mathrm{m}^{-1}$. It proves that there is a wide range of the solid solution temperature for 7A09 aluminum alloy. However, when the temperature is higher than $500^{\circ} \mathrm{C}$, the tensile strength and yield strength drop suddenly.

\subsection{Influence of water quenching temperature on mechanical properties and conductivity}

The influence of the water quenching temperature on the mechanical properties and conductivity of 7A09 aluminum alloy is shown in Fig. 3 .

As seen in Fig. 3, with the increase of water temperature, the tensile strength and yield strength drop continuously while the elongation rises gradually. The 
tensile strength and yield strength drop slowly below $40^{\circ} \mathrm{C}$, but once the temperature is above $40^{\circ} \mathrm{C}$, they drop remarkably. When the temperature is $40^{\circ} \mathrm{C}$, the tensile strength and yield strength are 570 and $495 \mathrm{MPa}$, respectively. The conductivity also rises below $40^{\circ} \mathrm{C}$ and then drops above $40^{\circ} \mathrm{C}$, and the maximum of the conductivity is $19.51 \mathrm{MS} \mathrm{m}^{-1}$. This indicates 7A09 aluminum alloy is sensitive to the cooling rate.

When the water quenching temperature is much too high, the cooling rate is slow, and thus the solid solutions dissolve during the cooling process. Therefore, the nucleation number during aging treatment drops, which coarsens the precipitates and weakens the strengthening effect of aging treatment. As a result, the tensile strength and yield strength decrease obviously. Contrarily, when the water temperature is below $40^{\circ} \mathrm{C}$, the cooling rate is significant, and there is not enough time for the second phase to nucleate and precipitate at the grain boundary, which makes the concentration of solute atoms higher. During aging, many second phases can uniformly precipitate, and their sizes have no big difference. So, the mechanical properties of the 7A09 alloy are promoted. However, the elongation is not mainly determined by the nucleation number during the aging process.

The concentration of solute atoms and the scattering of the electron affect the alloy conductivity. When the water temperature becomes higher, the precipitated metastable phases are much more, and the solute atoms that remain in the matrix are less, and the concentration of solute atoms becomes lower. Consequently, the conductivity gradually becomes higher. However, when the water temperature exceeds $40^{\circ} \mathrm{C}$, although the decrease of the concentration of solute atoms leads to the increase of the conductivity, the scattering of the alloy electrons also plays a key impact on the conductivity. The conductivity decrease caused by the scattering of the electrons is greater than the conductivity increase resulting from the solute atoms, so the conductivity gradually drops with the water temperature.

Therefore, the water quenching temperature should be kept below $40^{\circ} \mathrm{C}$. Contrarily, to avoid the quenching crack caused by excessive stress, the cooling rate must be slow. So, the water temperature must be high, which is contradictory to the requirement of low water temperature due to improving the strength. As a choice, the water quenching temperature is as low as possible on the condition that the stress cracks do not occur.

\subsection{Influence of transfer time before quenching on mechanical properties and conductivity}

Figure 4 shows the influence of the transfer time

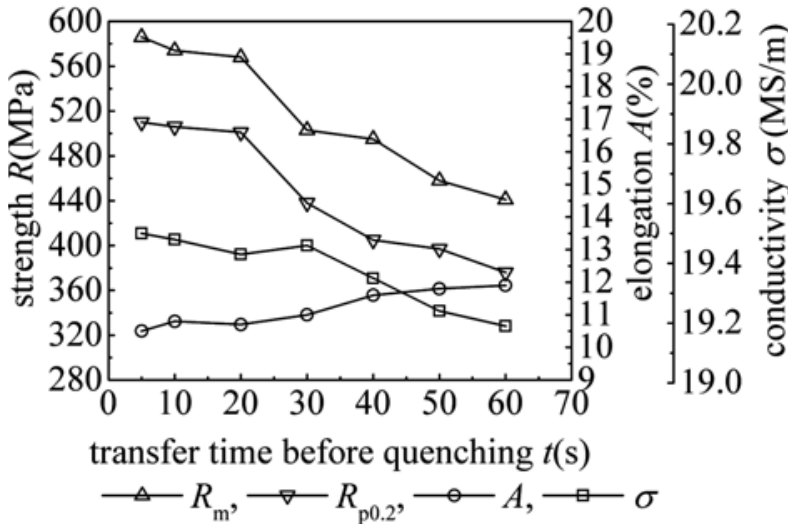

Fig. 4. Influence of transfer time before quenching on mechanical properties and conductivity.

before quenching on the mechanical properties and conductivity of 7A09 aluminum alloy.

The strength and conductivity always keep the tendency of decrease while the elongation rises all the time. When the transfer time before quenching is less than $20 \mathrm{~s}$, a little influence on four properties can be found. However, the transfer time is higher than $20 \mathrm{~s}$, the tensile strength $R_{\mathrm{m}}$, yield strength $R_{\mathrm{p} 0.2}$ and conductivity $\sigma$ drop quickly while the elongation $A$ rises gradually. So the transfer time should be kept within $20 \mathrm{~s}$. This can be explained as follows:

Because of additives of Mn and Cr, 7A09 aluminum alloy is sensitive to the quenching. Before the alloy was put into the water, it was cooled in the air, and the cooling rate was very small. When the transfer time before quenching was extended, there was plenty of time for the second phase to nucleate on the grain boundary and grow up to a certain extent. According to Ostwald ripening mechanism [13, 14], the second phase can absorb the solute atoms near the grain boundary and continue to grow up during aging. It leads to a poor area of solute atoms near the grain boundary and makes the precipitation of new second phase on the grain boundary difficult. So, the distribution of the precipitated phases on the grain boundary is discontinuous, and their size difference is too big. Moreover, the supersaturated vacancy concentration after quenching differs at different areas. During the cooling process, the vacancy diffuses to the grain boundary, and it causes the decrease of the vacancy concentration near the grain boundary. However, the vacancy away from the grain boundary has no space to diffuse, and thus the concentration is relatively higher. As a result, a concentration gradient is formed. The longer the transfer time is, the more disappeared vacancy in the grain boundary is. During aging, GP zone cannot appear in the area that is lower than the critical vacancy concentration, and thus a precipitationfree zone forms $[15,16]$. So, if the transfer time is 


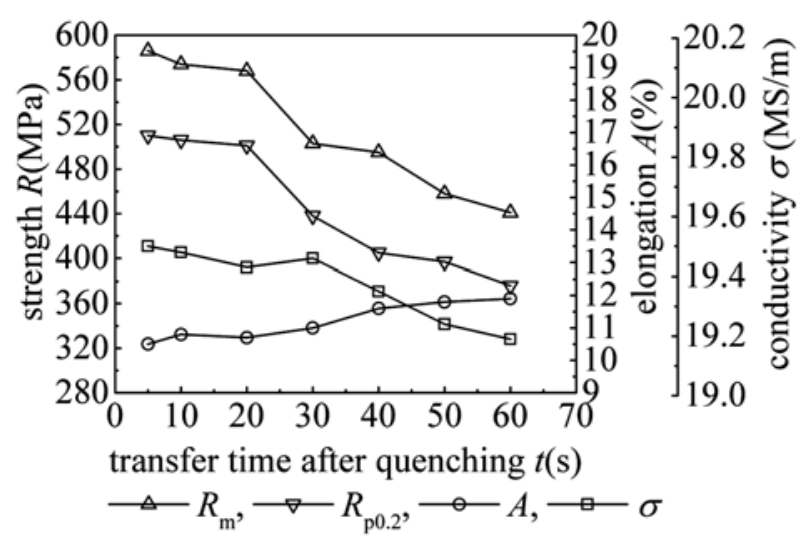

Fig. 5. Influence of delay time after quenching on mechanical properties and conductivity.

extended, the width of the precipitation-free zone becomes significant, and the mechanical properties and conductivity of alloy are deteriorated.

\subsection{Influence of delay time after quenching on mechanical properties and conductivity}

Figure 5 demonstrates the influence of the delay time after quenching on the mechanical properties and conductivity.

The tensile strength and yield strength are on the decline as a whole with the delay time. Before $8 \mathrm{~h}$, the strengths drop quickly while the elongation and conductivity rise continuously with the increase of the delay time. When the delay time is $8 \mathrm{~h}$, the tensile strength and yield strength achieve the minimum of 513 and $435 \mathrm{MPa}$, and the elongation and conductivity reach the maximum of $12.1 \%$ and $19.45 \mathrm{MS} \mathrm{m}^{-1}$. From 8 to $24 \mathrm{~h}$ a rebound of the mechanical properties and conductivity appears, and the strengths rise while the elongation and conductivity drop. When the delay time is more than $24 \mathrm{~h}$, the mechanical properties and conductivity of 7A09 alloy achieve a stable state. At $72 \mathrm{~h}$, they are $R_{\mathrm{m}}=551 \mathrm{MPa}, R_{\mathrm{p} 0.2}=489 \mathrm{MPa}$, $A=10.3 \%, \sigma=19.19 \mathrm{MS} \mathrm{m}^{-1}$, which are slightly lower than the values for $2 \mathrm{~h}$ that are $R_{\mathrm{m}}=568 \mathrm{MPa}$, $R_{\mathrm{p} 0.2}=501 \mathrm{MPa}, A=10.7 \%, \sigma=19.37 \mathrm{MS} \mathrm{m}^{-1}$.

In fact, this obvious delay time effect began once the quenching was done. It is related to the dissolution of GP zone [17]. Along with the extension of the delay time, a large number of partial polygroups form, and thus the concentration of solute elements in solid solutions is greatly reduced. During the artificial aging, the GP zones that are less than the critical size resolve back to the solid solution, and it reduces the number of the precipitation strengthening phase. So, the strengths of the alloy reduce. However, if the delay time continues to be extended, those GP zones that are less than the critical size are likely to grow up to the stable crystal nucleus. Therefore, the delay time effect became weak, and the mechanical properties of the alloy began to recover. Considering the actual production situation, the delay time after quenching is confined into $2 \mathrm{~h}$. If there is not enough time, the artificial aging can be performed after the delay time of $24 \mathrm{~h}$, which also can get ideal comprehensive performances.

\section{Conclusions}

The mechanical properties and conductivity keep relatively stable when the solid solution temperature is at $460-490^{\circ} \mathrm{C}$, but the over-burn appears once the temperature exceeds $500^{\circ} \mathrm{C}$. When the water quenching temperature and the transfer time before quenching are above $40^{\circ} \mathrm{C}$ and $20 \mathrm{~s}$, the strengths and conductivity drop remarkably. Before $8 \mathrm{~h}$, the strengths drop gradually while the elongation and conductivity rise continuously. At the range of $8-24 \mathrm{~h}$ there is an opposite change to the previous $8 \mathrm{~h}$. Once it exceeds $24 \mathrm{~h}$, the mechanical properties become stable. Therefore, the optimal quenching parameters are: the solid solution temperature is $460-490^{\circ} \mathrm{C}$, and the water quenching temperature and the transfer time before quenching are below $40^{\circ} \mathrm{C}$ and $20 \mathrm{~s}$, respectively, and the delay time after quenching is below $2 \mathrm{~h}$ or above $24 \mathrm{~h}$.

\section{Acknowledgements}

This research was financially supported by the Natural Science Foundation of Heilongjiang Province (F201213) and the Natural Science Foundation of China (51105121).

\section{References}

[1] Grechnikov, F. V., Dem'yanenko, E. G., Popov, I. P.: Russ. J. Non-Ferr. Met., 56, 2015, p. 15. doi:10.3103/S1067821215010083

[2] Nakai, M., Eto, T.: Mater. Sci. Eng. A, 285, 2000, p. 62. doi:10.1016/S0921-5093(00)00667-5

[3] Zhang, H., Nagaumi, H., Cui, J.: Mater. Sci. Eng. A, 448, 2007, p. 177. doi:10.1016/j.msea.2006.10.063

[4] Zuo, Y., Nagaumi, H., Cui, J.: J. Mater. Process. Tech., 197, 2008, p. 109. doi:10.1016/j.jmatprotec.2007.06.020

[5] Wang, W., Jia, B., Luo, S.: Trans. Nonferrous Met. Soc. China, 19, 2009, p. 377. doi:10.1016/S1003-6326(10)60065-9

[6] Luo, J., Li, M. Q., Ma, D. W.: J. Mater. Process. Tech., 212, 2012, p. 1039. doi:10.1016/j.jmatprotec.2011.12.012

[7] Chen, Q., Xia, X., Yuan, B., Shu, D., Zhao, Z.: Mater. Sci. Eng. A, 588, 2013, p. 395. doi:10.1016/j.msea.2013.09.040 
[8] Senkov, O. N., Senkova, S. V., Shagiev, M. R.: Metall. Mater. Trans. A, 39, 2008, p. 1034. doi:10.1007/s11661-008-9485-6

[9] Starink, M. J., Li, X. M.: Metall. Mater. Trans. A, 34, 2003, p. 899. doi:10.1007/s11661-003-0221-y

[10] Senkov, O. N., Shagiev, M. R., Senkova, S. V., Miracle, D. B.: Acta Mater., 56, 2008, p. 3723. doi:10.1016/j.actamat.2008.04.005

[11] Antipov, V. V., Senatorova, O. G., Tkachenko, E. A. Vakhromov, R. O.: Met. Sci. Heat. Treat., 53, 2012, p. 428. doi:10.1007/s11041-012-9410-x

[12] Wang, G. S., Zhao, Z. H., Zhang, Y. H., Cui, J. Z.: T. Trans. Nonferrous Met. Soc. China, 23, 2013, p. 2537. doi:10.1016/S1003-6326(13)62765-X
[13] Philippe, T., Voorhees, P. W.: Acta Mater., 61, 2013, p. 4237. doi:10.1016/i.actamat.2013.03.049

[14] Baldan, A.: J. Mater. Sci., 37, 2002, p. 2171. doi:10.1023/A:1015388912729

[15] Ogura, T., Hirosawa, S., Hirose, A., Sato, T.: Mater. Trans., 52, 2011, p. 900. doi:10.2320/matertrans.L-MZ201123

[16] Bernardin, J. D., Mudawar, I.: Int. J. Heat Mass Trans., 38, 1995, p. 863. doi:10.1016/0017-9310(94)00204-9

[17] Deschamps, A., Brechet, Y.: Scripta Mater., 39, 1998, p. 1517. doi:10.1016/S1359-6462(98)00357-1 